\title{
Solvability for time-fractional semilinear parabolic equations with singular initial data
}

\author{
Marius Ghergu ${ }^{1}$, Yasuhito Miyamoto², and Masamitsu Suzuki² \\ ${ }^{1}$ University College Dublin \\ ${ }^{2}$ The University of Tokyo
}

November 24, 2021

\begin{abstract}
We discuss the existence and nonexistence of a local and global-in-time solution to the fractional problem $\$ \$ ¥ b e g i n\{$ cases $\}$ $¥$ partial_t`\{¥alpha\}u= $¥$ Delta u+f(u) \& x ¥in¥Omega, ¥ 01\$ one has $\$|f(¥ x i)-f(¥ e t a)| ¥ l e C(1+|¥ x i|+\mid ¥ \text { eta } \mid)^{\wedge}\{$ p- 1$\} \mid ¥ x i-¥$ eta $\mid \$$ for all $\$ ¥ x i$, ¥eta ¥in $¥ R \$$. Particular attention is paid to the doubly critical case $\$(p, r)=(1+2 / N, 1) \$$.
\end{abstract}

\section{Hosted file}

2021-11-14.pdf available at https://authorea.com/users/447824/articles/546755-solvabilityfor-time-fractional-semilinear-parabolic-equations-with-singular-initial-data 